\title{
Impact of Quality Certification on Used Merchandise Transaction Behavior in Developing Countries, Involving Retailers and Consumers
}

\author{
Syed Abdul Rehman Khan',2, Adeel Shah ${ }^{3,4}$ \\ ${ }^{1}$ School of Management and Engineering, Xuzhou University of Technology, Xuzhou, China \\ ${ }^{2}$ Beijing Key Laboratory of Urban Spatial Information Engineering, Beijing, China \\ ${ }^{3}$ College of Business Management (CBM) Institute of Business Management, Karachi, Pakistan \\ ${ }^{4}$ Business School, UniKL (University of Kuala Lumpur), Kuala Lumpur, Malaysia \\ Email: sarehman_csco@yahoo.com, adeelshah@mail.com
}

How to cite this paper: Khan, S. A. R., \& Shah, A. (2021). Impact of Quality Certification on Used Merchandise Transaction Behavior in Developing Countries, Involving Retailers and Consumers. Open Journal of Social Sciences, 9, 456-464.

https://doi.org/10.4236/jss.2021.910032

Received: September 18, 2021

Accepted: October 26, 2021

Published: October 29, 2021

\begin{abstract}
The trade-in of used merchandise globally is high, as it allows the consumer to satisfy their needs at a lesser price. As the category grows over time, the quality requirement and assurance are also increasing and supported with relevant quality certification. For understanding the quality certification in used merchandise, the paper explores the evolutionary process of the phenomena. The research attempts to create an evolutionary game model encompassing retailers and consumers trading used merchandise. Further, the model used for the analysis assumes that retailers have examined and repair the (E and $\mathrm{R}$ ) capability of the used inventory. The model suggests that purchase and selling prices do not affect the stable evolutionary strategy (ESS); however, the cost of quality certification significantly impacts the model. The $\mathrm{E}$ and R capability of retailers impact the transaction as it reduces the price of used merchandise. The transaction cost and utility of the merchandise are motivating factors for the used market. Based on the research outcomes, government regulators should participate in the used merchandise transaction by providing a low-cost quality certification. The governmental authorities should intercede to offer a fair environment for both retailers and consumers and earn revenue as a minimum fee on the transaction.
\end{abstract}

\section{Keywords}

Used Merchandise, Certification, Transactions, Game Theory 


\section{Introduction}

Due to their evolved society and culture, developed countries have erected laws and regulations to safeguard the interests of all parties in a business transaction, whether seller or buyers (Xiao, 2020). However, in contrast, in developing countries, the law does not fully protect consumers. The cost of dispensation is high, and it still evolves to cover all aspects, especially the buyer and seller relationship for used business transactions (Kwarteng et al., 2018). However, in comparison, online selling in developing countries has traceability inbuild for a higher satisfaction level for consumers: a time frame is given to experience and inspects the new merchandise (Cao et al., 2018). According to Cao et al. (2018), the return merchandises increase the used merchandise inventory. The inventory increase of used merchandise and traceability gives retailers advantages, which could also benefit consumers if government authorities issue a quality certification (Cholez \& Trompette, 2020; Fathalla et al., 2020; Huang et al., 2020).

The low-income consumer in a developing country could benefit from such used merchandise as its acquisition is the cost is low (Chukova \& Shafiee, 2013; Kwarteng et al., 2018). According to Chukova \& Shafiee (2013), the government authorities in developing countries must maintain a balance between supplier and customer and dispense justice for consumer complaints. The government, while administering justice, also ensures that the economic market remains intact (Thavalingam \& Karunasena, 2016). Consumers sometimes also complain to authorities of faulty merchandise, resulting in the retailer being punished (Chukova \& Shafiee, 2013). In such a situation, the retailer's counter-strategy is to sell at a lesser price to avoid consumer complaints as such merchandise is not certified. After inspecting and testing, the Chinese authorities warrant the used inventory through rules known as "Chinese General Rules of the Used Goods Qualification." However, the retailer if choose to cooperate has to pay the authorities a certain amount as service charges for inspection and testing of the used merchandise. Besides government inspection the retailers can also use its capability of $\mathrm{E}$ and $\mathrm{R}$ in order to reduce after sale customer complains.

The capability ensures that retailers examine the merchandise and any fault repair before selling it to the customer. Both parties in the transaction would play the game to seek advantage as retailers would like to avoid government testing while the consumer would try to ensure that they buy the certified merchandise at the lowest price. As the trade of used merchandises increases, customers and retailers can learn from the completed transaction to make the right decision (Silveira \& Vasconcelos, 2020). The profiteering by retailers will not reduce until the transactions become stable. The stable state is known as the "evolution processing of used merchandises transaction." The used transaction game between retailers and consumers is shown in Figure 1.

The game of winning over the other side directs the current study to apply evolutionary game theory to understand the insights and study the transactional competition between retailers and used merchandise buyers. The most significant 


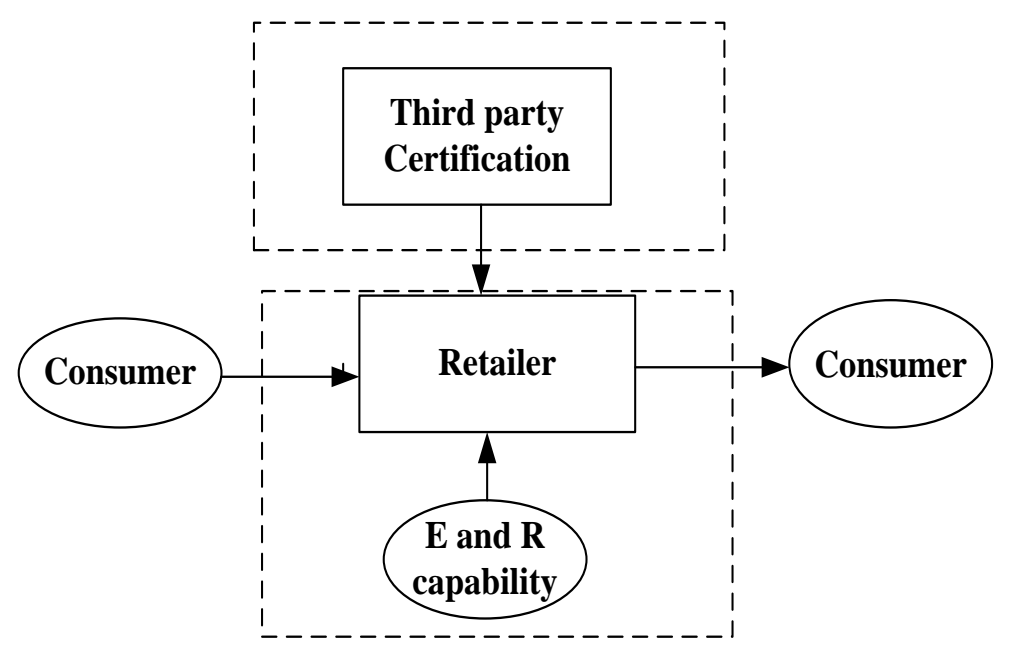

Figure 1. Retailers and consumers are playing a transactional game.

contributor to the used market is the retailers who supply the merchandise (Xiao, 2020). The study gives a fresh perspective in the context of used merchandise transaction theory to contribute academically.

\section{Literature Review}

\section{Leagile Strategy and Organizational Performance}

The growing environmental and social issues are the main factors that are causing much attention for scrapping and replacing merchandise (Huang et al., 2020; Kleber et al., 2012; Yu et al., 2021). Whereas trade-in means that a consumer trades old merchandise for buying new merchandise (Zhu et al., 2016), the retailer plays a significant role in the transaction. The research by Zhu et al. (2016) uses Nash Equilibrium to study retailer role in a trade-in; the study results suggest that retailer role is a competitive advantage that impacts financial performance. Similarly, Xiao's (2020) study on retailers' inclination to engage in trade-in highlights regular customers as an essential factor that increases and impacts retailer inclination to engage.

Besides retailers and customers as contributing factors in trade-in transactions, Huang et al. (2014) explore the role of government. The study reveals that financial gains are significant to attract retailers to trade-in for increase resource utilization to impact environment protection. The chief benefit of better resource utilization of virgin raw material is that government authorities allow retailers and customers to engage in trade-in. Another critical study in the similar context of the trade-in is by Cao et al. (2018): the trade-in channel and their cost on the transaction. The study suggests that logistic cost is significant for brick and wall retailers than online or offline collection channels. As the stock of number used merchandises increases, it reflects that more research requires for future development.

The current aim of the research at hand is to highlight the insights in the send-hand merchandise transaction between customers and retailers. The essen- 
tial requirement of the transaction is to have fairness and balance between both parties, which results in socio-economic benefit. The trade between both customer and retailer has bounded reality constraints, thus requires applying evolution game theory.

The used trade study by Yu et al. (2020) uses evolutionary game theory in automotive recycling, reflecting between customer and government. Similarly, in the context of evolutionary game theory, $\mathrm{Su}$ (2020) uses the same technique to propose an evolutionary game model that studies stable strategies between government, recyclers, and waste producers.

Fang et al. (2020) use evolutionary game theory to propose a certification model in bounded rationality. The primary player in the game theory pressurizes small players to collaborate. However, the result can be in favor of a defensive approach which results in bearing the pressure. Kolokoltsov (2017), based on primary player and small players interactions, has proposed an evolutionary inspection game on conflict interaction in the context of a larger class. Kolokoltsov (2017) divides the groups into two (retailer and consumers); the two groups constitute small players. The retailers will be absorbing the pressure from the customer group.

Further, the model assumes that government would slap punitive action against retailers in case of any complaints from the customer. Based on the literature review of the evolutionary game model and limited rationality of customers and retailers, the study proposes a model on used merchandise transactions for analysis. The model also uses the $\mathrm{E}$ and $\mathrm{R}$ capability of a retailer as a factor. Based on the investigation, the study brought forward the policy implications and recommendations that will contribute both academically and practically to used merchandise.

\section{Model and Results}

\subsection{Model}

Based on sellers E and R capability, the research aims to study the behavior evolution process of customers and sellers through used merchandises transaction. By employing E and R capability, the sellers can decrease complaints from used merchandise buyers. The resulting would be two situations in the construction of a game model for used merchandise. In the first situation, the $\mathrm{E}$ and $\mathrm{R}$ capability is present in sellers, while in the second situation, it is missing. Following are the parameters in the used transaction game model:

$P$, The merchandise selling price.

$C_{r}$, The merchandise buying price.

$c_{c}$, Used merchandise certification cost.

$c_{s}$ Excess costs bear by the retailer on the merchandise without certificates compared to certified inventory that buyer is demanding.

$\rho$, Buyer knowledge of proper protection's coefficient.

$\xi$, Retailer's E and R capability's coefficient. 
$K$, Punitive action by government authorities.

$e_{1}$, the utility of buying used certified merchandise.

$e_{2}$, the utility of buying used certified inventory without customer intention to purchase certified merchandise.

$e_{3}$, the utility of buying used non-certified merchandise, where buyer intents to buy accredited merchandise.

$e_{4}$, the utility of buying used non-certified inventory, where buyer intents to buy non-certified merchandise., $e_{1}>e_{2}>e_{4}>e_{3}$.

The model assumes that sellers choose a rate to certify the used item strategy. A is $x(t)$ and $1-x$ is the strategy B where sellers intents not to approve the used item. Also, $y$ are buyers who aim to purchase certified used merchandise (C), and 1- $y$ are buyers that have no aim to buy certified used inventory (D).

1) Scenario 1: The sellers are qualified QCs, and they will not sell the faulty merchandise to the buyers. Thus, for the sellers, the reproduced dynamic equation for strategy A, and for the buyers, the reproduced dynamic equations for strategy $\mathrm{C}$ respectively are:

$$
\begin{gathered}
\frac{d x}{d t}=x(1-x)\left[(\rho-\xi) K+y c_{s}-c_{c}\right] \\
\frac{d y}{d t}=y(1-y)\left[x\left(e_{1}-e_{2}\right)+(1-x)\left(e_{3}-e_{4}\right)\right]
\end{gathered}
$$

When $\frac{d x}{d t}=0$, then, $x^{*}=0,1, y^{\prime}=\frac{c_{c}-(\rho-\xi) K}{c_{s}}$.

When $\frac{d y}{d t}=0$, then, $y^{*}=0,1, x^{\prime}=\frac{e_{4}-e_{3}}{e_{1}-e_{2}+e_{4}-e_{3}}$, and $\frac{e_{4}-e_{3}}{e_{1}-e_{2}+e_{4}-e_{3}}>0$

Therefore, the stability of both parties (buyers and sellers) can be shown below in Figures 1-2, when $c_{s}>c_{c}-(\rho-\xi) K>0$.

2) Scenario 2: The sellers are unqualified QCs (E and R), and they are likely to sell the faulty merchandise to the buyers. Thus, for the sellers, the reproduced dynamic equation for strategy $\mathrm{A}$, and for the buyers the reproduced dynamic

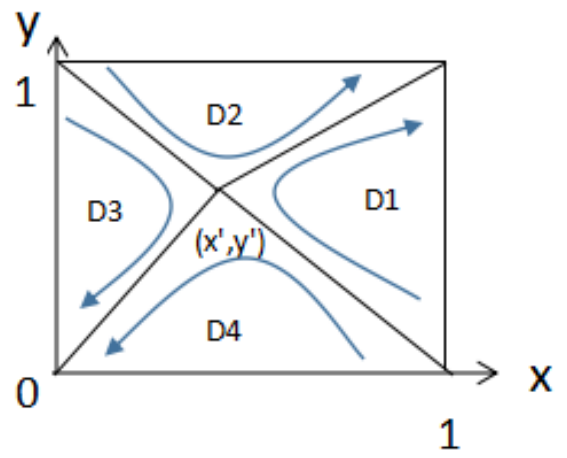

Figure 2. The used transaction behavior evolution process of sellers and buyers when $c_{s}>c_{c}-(\rho-\xi) K>0$. 
equation for the strategy $\mathrm{C}$ respectively are,

$$
\begin{gathered}
\frac{d x}{d t}=x(1-x)\left(\rho K+y c_{s}-c_{c}\right) \\
\frac{d y}{d t}=y(1-y)\left[x\left(e_{1}-e_{2}\right)+(1-x)\left(e_{3}-e_{4}\right)\right]
\end{gathered}
$$

When $\frac{d x}{d t}=0$, then, $x^{*}=0,1, y^{\prime}=\frac{c_{c}-\rho K}{c_{s}}$.

When $\frac{d y}{d t}=0$, then, $y^{*}=0,1, \quad x^{\prime}=\frac{e_{4}-e_{3}}{e_{1}-e_{2}+e_{4}-e_{3}}$, and $1>\frac{e_{4}-e_{3}}{e_{1}-e_{2}+e_{4}-e_{3}}>0$.

\subsection{Results}

1) Scenario 1 : The function $(1,2,3,4)$ presents the buying price $c_{r}$ and the selling price $P$ of the used merchandise, which does not impact the ESS of the transaction game. Following the analysis of the model, it reflects that

$c_{s}>c_{c}-(\rho-\xi) K>0(1,1)$ and $(0,0)$ are ESS. Hence it proves that sellers of used merchandise would certify as more buyers would like to buy certified products. Concerning Figure 2, the ESS is established in the starting state both by buyer and seller. The location of starting from is D1 + D2; the ESS at this point will be $(1,1)$. When the starting start is at D3 + D4, the ESS will be $(0,0)$ the key of ESS when $c_{s}>c_{c}-(\rho-\xi) K>0$. While, when $c_{c}<(\rho-\xi) K$, established only one ESS that is $(1,1)$. The results suggest that both parties will opt to transition for certified used merchandise in any starting state irrespective of long-time interaction between both parties. Further analysis of scenario 1, when $c_{c}-(\rho-\xi) K>c_{s} \quad(0,0)$ suggests being the only ESS that reflects that for uncertified merchandise where certification is short of supply, the buyers intend not to certify such products.

2) Scenario 2: Scenario two results of the evolutionary game on used merchandise transactions do not correlate with buying and selling the merchandise. The sellers who do not possess the $\mathrm{E}$ and $\mathrm{R}$ capability will risk government punitive action to sell faulty merchandise. The results are somewhat like scenario 1 , with the addition of $\xi K$ that is corrective authority action. If $c_{s}>c_{c}-\rho K>0$ results to two ESS for the used inventory: $(0,0),(1,1)$ and the $\left(x^{\prime}, y^{\prime}\right)$ point, is essential as it can be the group game's ESS. If $c_{c}<\rho K$, in any initial state, the ESS will remain $(1,1)$. If $c_{c}-\rho K>c_{s}$ in any initial state, the ESS of transaction of the evolutionary game will be $(0,0)$.

\section{Discussion}

The research aims to seller's and buyer's behavior for used certified merchandise during its transaction between the two stated groups. The buying and selling prices of the used merchandise do not influence the behavior of buyers and sellers in the case of non-certified merchandise. Nevertheless, the certification cost 
has an influence on buyer and seller transactional behavior. Likewise, Thomas (2003) claimed used transaction cost substantially impacts buyers buying used merchandise requires fair market regulations. The used merchandise's low price is the crucial reason for buyers. However, the high cost of certification for use merchandise diminishes the price advantages for both seller and buyer.

According to Santos et al. (2021), the E and R capability for used merchandise is an essential factor that impacts the market's socio-economic aspect. Similarly, the research at hand also shows that seller E and R capability of seller affects the transaction behavior of both buyer and seller in used merchandise. The $\mathrm{E}$ and $\mathrm{R}$ capability is a competitive advantage in which sellers could provide after-sales services for used items and brand new merchandise.

Every passing day the awareness of consumer rights is increasing, and buyer demands the transparency in used merchandise transaction. The sellers have to match the demand for transparency in the transaction. Compared to online merchants, offline sellers have better traceability (Cao et al., 2018). However, once the capability $\mathrm{E}$ and $\mathrm{R}$ is created, the trust of the online merchant will also increase for the consumer. Once the capability is developed, the buyers have a low-cost option and engage with a government agency for used merchandise. The ability will enable buyers to rectify if any faulty merchandise is sold to the buyer and avoid punitive action in case of complaint. The advantage of price and transparency in the used inventory are essential factors in the transaction; however, the government should provide justice to fraudulent sellers who do not rectify faults in used merchandise.

According to Jia and $\mathrm{Li}$ (2019), the seller of certified products is a strong competitor compared to merchants selling low-quality new merchandise. The seller of used merchandise creates similar transparency of a new product; the price advantage of a used merchant could provide a real competitive advantage to the merchant.

\section{Conclusion}

The research explores the behavior evolution process for used certified merchandise during its transaction between buyers and sellers with their capability for E, and R. A game model is proposed based on evolutionary game theory. The success is based on the advantage gained by both buyer and seller during the transaction. The cost of certification is an essential factor for sellers' decision-making process. However, the seller's $\mathrm{E}$ and $\mathrm{R}$ capability is a substation for used products quality certificates to complaints in case of any faults in the sold merchandise. However, the importance of quality certification for used inventory cannot be ignored, as it increases the utility for the buyer during the transaction. Besides, the $\mathrm{E}$ and $\mathrm{R}$ are still the most cost-effective method compared to low-cost government certification for used merchandise for buyers.

Therefore in the light of the results from the research, it is critical to suggest that a system should be in place to provide transparency for transactions in the 
used product so the rights of buyers can be protected and complaints could be rectified in case of faulty merchandise. The government should review the quality certification charges. It would encourage the recyclers to enter the used merchandise market, which could positively impact a country's economy and sustainability. Besides certification, the results also reveal that sellers should create $\mathrm{E}$ and R capability to create good relations with buyers as all complaints would be rectified because of the developed capability.

Therefore, the created capability can reduce the transactional cost and attract buyers to the used merchandise market. The buyer's demands could improve utilities provided by buyers resulting in a growing, and active used merchandise market could establish. The research contributes a new point of view for the literature on used merchandise transactions and provides practical suggestions to increase the used merchandise market.

\section{Acknowledgments}

This research is supported by the Beijing Key Laboratory of Urban Spatial Information Engineering (NO. 20210218).

\section{Conflicts of Interest}

The authors declare no conflicts of interest regarding the publication of this paper.

\section{References}

Cao, K., Wang, J., Dou, G., \& Zhang, Q. (2018). Optimal Trade-In Strategy of Retailers with Online and Offline Sales Channels. Computers \& Industrial Engineering, 123, 148-156. https://doi.org/10.1016/j.cie.2018.05.028

Cholez, C., \& Trompette, P. (2020). A Mundane Infrastructure of Energy Poverty: The Informal Trading of Second-Hand Car Batteries in Madagascar. Journal of Material Culture, 25, 259-288. https://doi.org/10.1177/1359183519895048

Chukova, S., \& Shafiee, M. (2013). One-Dimensional Warranty Cost Analysis for Second-Hand Items: An Overview. International Journal of Quality \& Reliability Management. https://doi.org/10.1108/02656711311299827

Fang, L., Shi, G. Z., Wang, L. H., Li, Y. J., Xu, S. J., \& Guo, Y. C. (2020). Incentive Mechanism for Cooperative Certification: An Evolutionary Game Approach. Information Sciences, 527, 369-381. https://doi.org/10.1016/j.ins.2019.07.030

Fathalla, A., Salah, A., Li, K., Li, K., \& Francesco, P. (2020). Deep End-to-End Learning for Price Prediction of Second-Hand Items. Knowledge and Information Systems, 62, 4541-4568. https://doi.org/10.1007/s10115-020-01495-8

Huang, H., Tong, X., Cai, Y., \& Tian, H. (2020). Gap between Discarding and Recycling: Estimate Lifespan of Electronic Products by Survey in Formal Recycling Plants in China. Resources, Conservation and Recycling, 156, 104700. https://doi.org/10.1016/j.resconrec.2020.104700

Huang, J., Leng, M., Liang, L., \& Luo, C. (2014). Qualifying for a Government's Scrappage Program to Stimulate Consumers' Trade-In Transactions? Analysis of an Automobile Supply Chain Involving a Manufacturer and a Retailer. European Journal of Operational Research, 239, 363-376. https://doi.org/10.1016/j.ejor.2014.05.012 
Jia, D. F., \& Li, S. J. (2019). Impacts of Trade-In Program on Duopoly Competition with Merchandise Quality Differentiation and Used Market. Journal of Southeast University, 35, 516-521.

Kleber, R., Schulz, T., \& Voigt, G. (2012). Dynamic Buy-Back for Product Recovery in End-of-Life Spare Parts Procurement. International Journal of Production Research, 50, 1476-1488. https://doi.org/10.1080/00207543.2011.560202

Kolokoltsov, V. (2017). The Evolutionary Game of Pressure (or Interference), Resistance and Collaboration. Mathematics of Operations Research, 42, 915-944. https://doi.org/10.1287/moor.2016.0838

Kwarteng, M. A., Pilík, M., \& Juřičková, E. (2018). Beyond Cost Saving. Other Factor Consideration in Online Purchases of Used Electronic Goods: A Conjoint Analysis Approach. Management \& Marketing-Challenges for the Knowledge Society. https://doi.org/10.2478/mmcks-2018-0022

Santos, A. C. J., Cavalcante, C. A. V., \& Ribeiro, L. F. A. (2021). The Use of Second-Hand Items Based on Delay Time Modelling. Process Safety and Environmental Protection, 146, 118-125. https://doi.org/10.1016/j.psep.2020.08.041

Silveira, D., \& Vasconcelos, S. (2020). Essays on Duopoly Competition with Asymmetric Firms: Is Profit Maximization Always an Evolutionary Stable Strategy? International Journal of Production Economics, 225, 107592. https://doi.org/10.1016/j.ijpe.2019.107592

Su, Y. (2020). Multi-Agent Evolutionary Game in the Recycling Utilization of Construction Waste. Science of The Total Environment, 738, 139826. https://doi.org/10.1016/j.scitotenv.2020.139826

Thavalingam, V., \& Karunasena, G. (2016). Mobile Phone Waste Management in Developing Countries: A Case of Sri Lanka. Resources, Conservation and Recycling, 109, 34-43. https://doi.org/10.1016/j.resconrec.2016.01.017

Thomas, V. M. (2003). Demand and Dematerialization Impacts of Second-Hand Markets: Reuse or More Use? Journal of Industrial Ecology, 7, 65-78. https://doi.org/10.1162/108819803322564352

Xiao, L. Y. (2020). ESRB's and PEGI's Self-Regulatory “Includes Random Items” Labels Fail to Ensure Consumer Protection. International Journal of Mental Health and Addiction, 1-4. https://doi.org/10.1007/s11469-020-00329-6

Yu, K. H., Zhang, Y., Li, D., Montenegro-Marin, C. E., \& Kumar, P. M. (2021). Environmental Planning Based on Reduce, Reuse, Recycle and Recover Using Artificial Intelligence. Environmental Impact Assessment Review, 86, 106492. https://doi.org/10.1016/j.eiar.2020.106492

Zhu, X., Wang, M., Chen, G., \& Chen, X. (2016). The Effect of Implementing Trade-In Strategy on Duopoly Competition. European Journal of Operational Research, 248, 856-868. https://doi.org/10.1016/j.ejor.2015.07.053 